\title{
Recognition by Recombinant Autoimmune Thyroid Disease-derived Fab Fragments of a Dominant Conformational Epitope on Human Thyroid Peroxidase
}

Stefano Portolano, * Gregorio D. Chazenbalk, * Pui Seto, * J. Scott Hutchison, ${ }^{\star}$ Basil Rapoport, * and Sandra M. McLachlan *

*Thyroid Molecular Biology Unit, Veterans' Administration Medical Center and the University of California, San Francisco, California 94121; and ${ }^{\ddagger}$ Nichols Institute, San Juan Capistrano, California 92690-6130

\begin{abstract}
To characterize the nature of thyroid peroxidase (TPO) autoantibodies present in the sera of patients with autoimmune thyroid disease, we cloned three IgG1/kappa Fab fragments which bind ${ }^{125}$ I-TPO. This was accomplished by the molecular cloning and expression in bacteria of IgG gene fragments from B cells infiltrating the thyroid of a patient with Graves' disease. The three Fab fragments (SP2, SP4, and SP5) are coded for by a common heavy chain (VH1, D, JH3) and three related, but different, light chains (VK1, JK2). The SP Fab fragments bind specifically to TPO with high affinities $\left(6 \times 10^{-11}-2 \times 10^{-10}\right.$ M) comparable to those of serum TPO autoantibodies. TPO autoantibodies represented by the SP Fab fragments are present in all 11 patients studied, constitute a high proportion (36$72 \%$ ) of serum TPO autoantibodies in individual patients and interact with a conformational epitope on TPO. (J. Clin. Invest. 1992. 90:720-726.) Key words: thyroid peroxidase $\bullet$ autoantibody $\bullet$ epitope $\bullet$ autoimmunity
\end{abstract}

\section{Introduction}

Thyroid peroxidase (TPO), ${ }^{1}$ the primary enzyme involved in thyroid hormone synthesis, is a large $(\sim 107 \mathrm{kD})$ membranebound glycoprotein molecule whose cDNA has been cloned (1-3). TPO is a major target of the immune system in human autoimmune thyroid disease. Until the demonstration of their identity (3-7), TPO was studied as the "thyroid microsomal antigen" (8). IgG class autoantibodies with high affinity for TPO (9) are present in the sera of patients with Hashimoto's thyroiditis or Graves' disease and may play a role in thyroid destruction (8, 10-12).

Definition of the epitopes recognized by TPO autoantibodies is an important goal in understanding the pathogenesis of autoimmune thyroid disease. TPO autoantibodies appear to interact with different regions of the molecule. For example, some, but not all, TPO autoantibodies inhibit TPO enzymatic activity (13) and cross-react with myeloperoxidase or lactoperoxidase (14). At the molecular level, two epitopes for serum TPO autoantibodies have been defined $(15,16)$. Both of these epitopes are linear. However, extensive data from other antigen/antibody systems demonstrate that the majority of B cell

Address correspondence to Stefano Portolano, M.D., Veterans' Administration Medical Center, Thyroid Molecular Biology Unit (111T), 4150 Clement Street, San Francisco, CA 94121.

Received for publication 3 January 1992.

1. Abbreviation used in this paper: TPO, thyroid peroxidase.

The Journal of Clinical Investigation, Inc.

Volume 90, September 1992, 720-726 epitopes are discontinuous and highly conformational (17, 18 ). Further, decreased binding of TPO autoantibodies to denatured TPO $(19,20)$ suggests that the majority of serum TPO autoantibodies are not directed against linear epitopes.

Human, disease-associated monoclonal TPO autoantibodies will be invaluable in defining TPO epitopes. However, such monoclonal antibodies are exceptionally difficult to generate by conventional techniques (21). Recently, we obtained a human Fab fragment specific for TPO by cloning heavy and light chain immunoglobulin genes (22) from B cells infiltrating Graves' thyroid tissue (23). In the present study, we describe the isolation of two additional TPO-specific Fab fragments from this library, as well as the expression and characterization of all three Fab fragments. Our data indicate that TPO autoantibodies represented by these Fab fragments are present in all patients studied, constitute a high proportion of serum TPO autoantibodies in individual patients, and interact with a conformational epitope on TPO.

\section{Methods}

Molecular cloning of TPO-binding Fab fragments. Construction of the IgG1/kappa Fab fragment combinatorial cDNA library in the vector Immunozap (Stratacyte, La Jolla, CA) has been described previously (23). The source of the mRNA was Graves' thyroid tissue, known to contain IgG-secreting cells. The unamplified combinatorial library ( 3 $\times 10^{6}$ recombinants) was screened in XL1-Blue cells by conventional techniques (24) using secreted recombinant human TPO (25), affinity purified with mouse monoclonal anti-TPO, labeled with ${ }^{125}$ I to a specific activity of $\sim 10 \mu \mathrm{Ci} / \mu \mathrm{g}$ protein by the iodogen method (26). TPO-binding plaques were cloned to homogeneity and plasmids (Bluescript SK-) were excised from the Immunozap bacteriophage using the helper phage R408, according to the Stratacyte protocol. Nucleotide sequences were determined in both directions (27).

Preparation of soluble Fab fragments. Plasmid-bearing XL1 Blue cells were incubated overnight at $37^{\circ} \mathrm{C}$ in Luria-Bertani medium containing $1 \%$ glucose. After dilution in LB medium without glucose, cultures were further incubated at $37^{\circ} \mathrm{C}$ until the optical density of the cells reached $0.5(600 \mathrm{~nm})$. Protein synthesis was induced with $1 \mathrm{mM}$ isopropyl b-D-thiogalacto-pyranoside (Sigma Chemical Co., St. Louis, MO) for $1 \mathrm{~h}$ at $37^{\circ} \mathrm{C}$. The cells were then pelleted, frozen at $-20^{\circ} \mathrm{C}$, resuspended in $0.02 \mathrm{vol}$ of $10 \mathrm{mM}$ Tris pH 8.0 containing $2 \mu \mathrm{g} / \mathrm{ml}$ aprotinin, $1 \mu \mathrm{g} / \mathrm{ml}$ leupeptin, $1 \mu \mathrm{g} / \mathrm{ml}$ pepstatin, $0.1 \mathrm{mM}$ phenylmethylsulfonyl fluoride (all from Sigma). The suspension was sonicated, membranes pelleted by centrifugation at $4,000 \mathrm{~g}$ and the Fab fragments affinity purified from the supernatant using a Protein $G$ sepharose column (Pharmacia, Piscataway, NJ). The Fab proteins were 99\% pure as determined by SDS polyacrylamide gel electrophoresis (28).

Fab fragment binding to radiolabeled TPO. The interaction of the Fab fragments with ${ }^{125}$ I-TPO was investigated as previously described for thyroglobulin monoclonal artoantibodies (29). Briefly, duplicate aliquots of SP2, SP4, or SP5, ser..? ?y diluted in assay buffer $(0.15 \mathrm{M}$ $\mathrm{NaCl}$ containing $10 \mathrm{mM}$ Tris- $\mathrm{HCl} \mathrm{pH} 7.5$ and $0.5 \%$ bovine serum albumin $)$ were incubated with ${ }^{125} \mathrm{I}-\mathrm{TPO}(\sim 25,000 \mathrm{cpm})$ and mouse 
monoclonal antibody to human kappa light chains (QE11; Recognition Sciences, Birmingham, UK) in a total volume of $200 \mu \mathrm{l}$. After $1 \mathrm{~h}$ at room temperature, $100 \mu$ l donkey anti-mouse Sac-cel (IDS, Boldon, Tyne and Wear, UK) was added, and the incubation continued for 30 min. After vortexing, the mixture was centrifuged for $5 \mathrm{~min}$ at $1,000 \mathrm{~g}$ to sediment the immune complexes which were then counted to determine the percent radiolabeled TPO bound. The specificity of this interaction was assessed by the addition of increasing amounts $\left(10^{-12}\right.$ $\mathrm{M}-10^{-8} \mathrm{M}$ ) of unlabeled recombinant human TPO, human myeloperoxidase (Calbiochem Corp., La Jolla, CA) or bovine lactoperoxidase (Sigma). The affinities of the Fab fragments for TPO were determined by Scatchard analysis ( 30$)$.

Competition studies between Fab fragments and serum TPO autoantibodies. Sera from 11 patients with autoimmune thyroid disease were studied. All sera contained high levels of TPO autoantibodies (detectable by ELISA [31] at dilutions of 1:1,000 or greater). Binding of ${ }^{125}$ I-TPO by serum autoantibodies was measured by precipitating the antigen-antibody complex with Protein A (Pansorbin; Calbiochem) (9) in the presence of increasing concentrations of Fab fragments. The Fab fragment-TPO complex, lacking the $\mathrm{CH} 2$ domain of the Fc region, is not precipitated by Pansorbin. Duplicate aliquots of sera were incubated for $1 \mathrm{~h}$ at room temperature with ${ }^{125} \mathrm{I}-\mathrm{TPO}$, alone or with Fab fragments. Pansorbin $(100 \mu \mathrm{l})$ was added and the incubation continued for $30 \mathrm{~min}$. After addition of $1 \mathrm{ml}$ assay buffer (see above), the mixture was vortexed, centrifuged for $30 \mathrm{~min}$ at $1,000 \mathrm{~g}\left(4^{\circ} \mathrm{C}\right)$, supernatants removed by aspiration, and TPO remaining in the pellets counted. In preliminary experiments, we determined serum dilutions needed to provide binding values of $\sim 20 \%$ in the absence of Fab fragments. These dilutions ranged from 1:600-1:2,000. Nonspecific ${ }^{125}$ I-TPO binding in the presence of control serum without TPO antibodies was $2-5 \%$ of total $\mathrm{cpm}$ added. This value was subtracted from the values obtained with patients' sera in calculating the percent inhibition by the SP Fab fragments.

Competition studies between Fab fragments and serum TPO antibodies of different IgG subclasses. An ELISA was used for this purpose, similar to that previously described for TPO autoantibodies measured using thyroid microsomal antigen (32), with some modifications. Conditioned medium ( $50 \mu \mathrm{l}$ per well) from Chinese hamster ovary cells overexpressing a secreted form of TPO (25), was used to coat ELISA plates (Immulon 4; Dynatech Laboratories, Chantilly, VA) by incubation overnight at $4^{\circ} \mathrm{C}$ with an equal volume of bicarbonate buffer ( $\mathrm{pH}$ 9.3). Serum TPO autoantibodies of different IgG subclasses were detected with murine monoclonal antibodies (33) to human IgG1 and IgG4 (HP6012 and HP6011, respectively; Unipath Inc., Nepean, Ontario, Canada) and IgG2 (HP6014; Sigma). Serum TPO autoantibodies with lambda light chains were detected using murine monoclonal anti-human lambda ( $312 \mathrm{H}$; Recognition Sciences). The signal was developed with affinity-purified anti-mouse IgG conjugated to horseradish peroxidase (Sigma) and $o$-phenylene diamine $+\mathrm{H}_{2} \mathrm{O}_{2}$ as substrate and OD read at $492 \mathrm{~nm}$. None of these murine monoclonal antibodies bound to the Fab fragments. Competition studies were performed by incubating sera (appropriately diluted) with or without increasing concentrations of SP2 Fab fragment.

Screening of TPO CDNA fragment library. Construction of the library and the method used for screening has been described previously (34). Reactivity of Fab fragment SP2 was assessed using the murine anti-kappa antibody (QE11; Recognition Sciences) followed by affinity-purified anti-mouse IgG horseradish peroxidase conjugate (Cappel Laboratories, West Chester, PA). As a positive control, we used a murine monoclonal antibody ( $\# 40.28$ ), generated against denatured TPO (35), which recognizes a linear epitope expressed in this library.

Interaction between Fab fragments and denatured TPO. TPO in conditioned culture medium (described above) was reduced and alkylated using dithiothreitol and iodoacetamide (19). ELISA plates were coated with native or denatured TPO, as described above. Binding of SP2, SP4, and SP5 $\left(10^{-9} \mathrm{M}\right)$ was detected, as described above for serum TPO lambda autoantibodies, using monoclonal anti-kappa (QE11). Mouse monoclonal antibody (\#40.28, diluted 1:100) and control ascites (NS-1, diluted 1:50; Cappel) were included as positive and negative controls respectively.

\section{Results}

Nucleotide and derived amino-acid sequences of TPO-binding Fab fragments. Further screening of the Fab fragment combinatorial cDNA library for radiolabeled TPO binding yielded two additional Fab fragments (SP4 and SP5). The heavy chains of SP4 and SP5 were identical to that of previously isolated SP2 (23). The light chains of SP4 and SP5, although closely related to that of SP2, differed in their nucleotide (Figs. 1 and 3) and derived amino acid (Figs. 2 and 3 ) sequences. All three light chains are coded for by VK1 and JK2, the closest germ-line genes being HUMIGKLVJ (GenBank accession number D90158) and KV312 (36), respectively.

Regarding the VK region, the SP4 and SP5 amino acid sequences are more homologous $(90 \%)$ to HUMIGKLVJ than SP2 $(83 \%)$. Only the kappa chain of SP2 has a potential glycosylation site, N-X-S, in the CDR1 (Fig. 2). Unlike SP2, in which the $\mathrm{J}$ segment is identical to the germline gene $\mathrm{KV} 312$, SP4 and SP5 (which are identical to each other) have four nucleotide substitutions, one of which results in an $\mathrm{L}$ to $\mathrm{V}$ change (Fig. 3).

Specificity and affinity of TPO-binding Fab fragments. Binding of the SP2 Fab fragment to ${ }^{125}$ I-TPO was readily displaced by unlabeled TPO but not by myeloperoxidase or lactoperoxidase (Fig. $4 A$ ) . SP4 and SP5 displayed the same specificity for TPO (data not shown). As determined by Scatchard analysis, the affinities for TPO of all three Fab fragments were remarkably high (Fig. $4 B$ ). SP2 and SP5 displayed similar affinities $\left(K_{\mathrm{d}} \sim 6-8 \times 10^{-11} \mathrm{M}\right)$. The affinity of SP4 was slightly lower $\left(\sim 2 \times 10^{-10} \mathrm{M}\right)$.

Competition studies between Fab fragments and serum TPO autoantibodies. We determined the abilities of SP2, SP4, or SP5 to compete with TPO autoantibodies in patients' sera for binding to ${ }^{125} \mathrm{I}-\mathrm{TPO}$. Increasing amounts of SP2 $\left(10^{-10}\right.$ $10^{-7} \mathrm{M}$ ) progressively inhibited the binding to TPO by all of 11 sera from patients with autoimmune thyroid disease that were tested (Fig. 5). In the individual 11 sera, maximum inhibition ranged from 36 to $72 \%$. The results obtained for five of these sera were similar with all three Fab fragments: $55 \pm 2 \%$ (mean \% inhibition \pm SEM) for SP2, $49 \pm 8 \%$ for SP5, and $43 \pm 6 \%$ for SP 4 . Competition studies attempting to determine whether or not the inhibitory effects of SP2, SP4, and SP5 were additive were inconclusive because of the inability to attain high enough $\mathrm{Fab}$ fragment concentrations. Because SP2, SP4, and SP5 have identical heavy chains and similar light chains belonging to the same VK gene family, it is reasonable to assume that they bind to the same, or closely related, epitope. This assumption is supported by studies in mice demonstrating that high affinity binding to a specific epitope is usually achieved by recombination of the same heavy chain with light chains of the same family (37).

Competition studies between Fab fragments and serum TPO autoantibodies of different subclasses and lambda light chain. Sera from individual patients contain different proportions of TPO antibodies of subclasses IgG1 and IgG4 and, in some patients, $\operatorname{IgG} 2(32,38)$. We, therefore, investigated the effect of SP2 (as a representative Fab) on the inhibition of TPO binding to serum TPO autoantibodies of different subclasses. Data illustrating three different inhibition patterns among the 
KLVJ

VK-SP2

VK-SP 4

VK-SP 5

Consensus $\ldots$ CA ......................... . . . . .

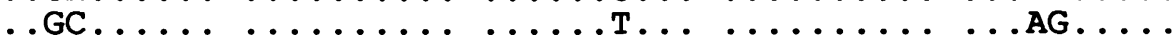

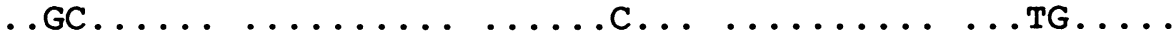

$\ldots$ GC ... ...... ..... ......... . . . .

GA--TCGTGA TGACCCAGTC TCCATC-TCC CTGTCTGCAT CTG--GGAGA
KLVJ

VK-SP2

VK-SP 4

VK-SP 5

Consensus $\ldots$ G................... ..GCA..A.T .AC...T.

.C..................................... $\ldots G \ldots \ldots \ldots \ldots$............... ..CCG..G.C .CC...T. .G.......................ACA..G.C .AA...T. CA-AGTCACC ATCA-TTGCC GGGCAAGT-A GA---TT-G- A--TATT-AA

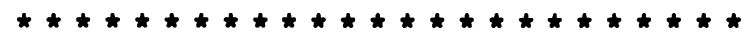
CDR1

KLVJ

VK-SP2

VK-SP 4

VK-SP 5

Consensus

$$
\begin{aligned}
& \ldots \ldots \ldots \text {...GA.A.............G....G..C.A.GC. }
\end{aligned}
$$

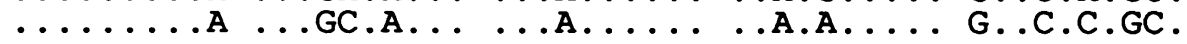

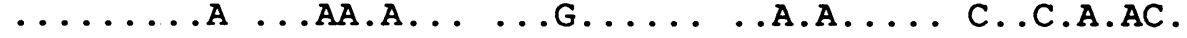

$$
\begin{aligned}
& \ldots \ldots \ldots \text {....GA.G............G.G.... . . . .A.GG. } \\
& \text { ATtGGTATC- GCA--A-CCA GGG-AAGCCC CT-A-CTCCT -AT-T-T--T } \\
& \text { * * }
\end{aligned}
$$

KLVJ

VK-SP 2

VK-SP 4

VK-SP 5

Consensus

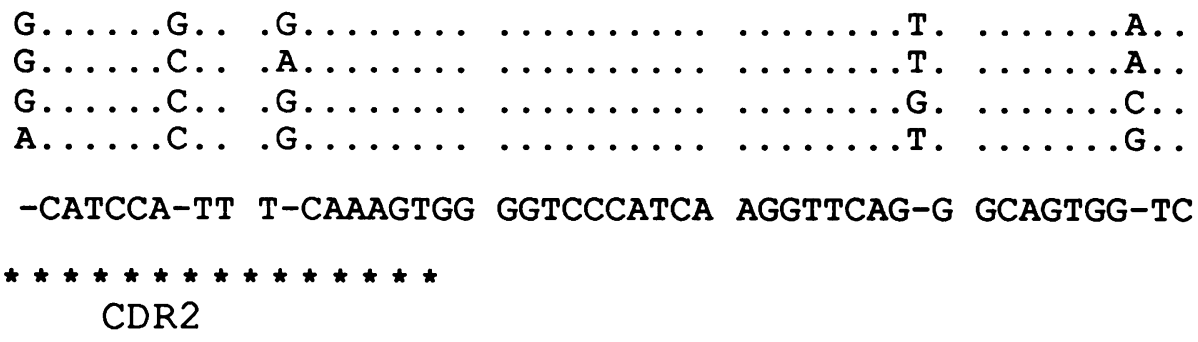

KLVJ

VK-SP 2

VK-SP 4

VK-SP 5

Consensus

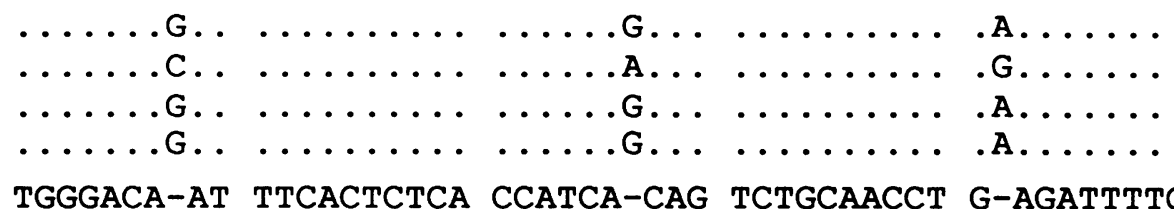

250

250

250

250

250
KLVJ

VK-SP2

VK-SP 4

VK-SP 5

Consensus

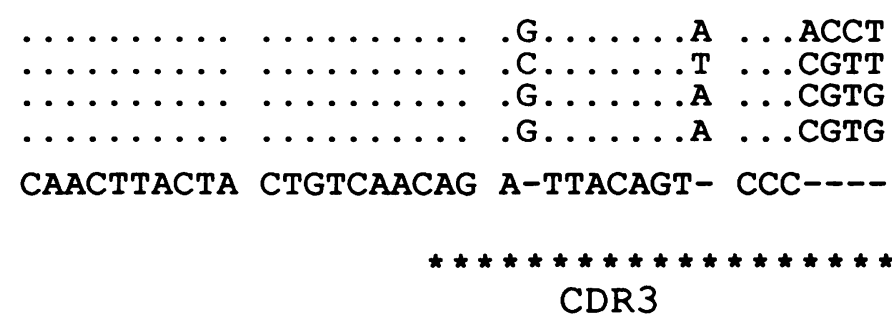

CDR3

Figure 1. Nucleotide sequences of the VK regions of TPO Fab fragments SP2, SP4, SP5, and the VK1 germline gene HUMIGKLVJ (GenBank accession number D90158) together with the consensus sequence for all four genes. Identical nucleotides are indicated by dots. The nucleotides at positions 3 and 4, which differ from the germline gene sequence, are mutations required to introduce the Sacl restriction site used to clone the light chain genes. The complementarity-determining regions (CDR) 1, 2, and 3 are indicated by asterisks. These light chain sequences are available from Genbank under accession numbers M95721 (sP2), M95722 (sP4), and M95723 (sP5). The sP2 heavy chain accession number is $\mathrm{M} 82813$. 
KLVJ

VK-SP2

VK-SP 4

VK-SP 5

Consensus

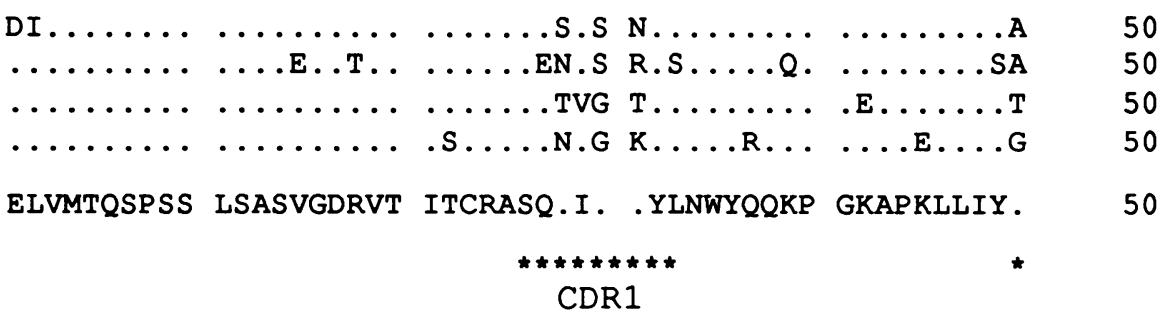

\begin{tabular}{|c|c|c|c|c|}
\hline $\begin{array}{l}\text { KLVJ } \\
\text { VK-SP2 }\end{array}$ & $\begin{array}{l}\ldots s \ldots \ldots \\
\ldots \ldots \ldots\end{array}$ & $\cdots \cdots \cdots \cdot$ & $\cdots \cdots$ & $\ddot{G} \ldots \ldots \cdots \cdots$ T.. \\
\hline VK-SP 4 & $\ldots \ldots \ldots$ & .R...... & $\ldots \ldots \ldots \ldots$ & $\ldots \ldots \ldots \ldots, \ldots v$ \\
\hline VK-SP 5 & T....... & $\ldots \ldots \ldots$ & $\ldots \ldots \ldots$ & $\ldots \ldots \ldots, \cdots v$ \\
\hline Consensus & $\begin{array}{l}\text { ASTLQSGVPS } \\
\star \star \star \star \star ~ \\
\text { CDR2 }\end{array}$ & RFSGSGSGTD & FTLTISSLQP & $\begin{array}{r}\text { EDFATYYCQQ SYSTPP } \\
\star \star \star \star \star \star \star \star ~ \\
\text { CDR } 3\end{array}$ \\
\hline
\end{tabular}

Figure 2. Derived amino acid sequence (in single-letter code) of VK regions of TPO Fab fragments SP2, SP4, SP5, and HUMIGKLVJ (GenBank accession number D90158) together with the consensus sequence. Identical residues are indicated by dots and CDR1, CDR2, and CDR3 are indicated by asterisks. The amino acid residues at positions 1 and 2 , which differ from the germline gene, are encoded by the SacI restriction site introduced for cloning the light chain genes.

9 sera analyzed are shown (Fig. 6). In one patient (Fig. $6 \mathrm{~A}$ ), IgG4 TPO antibody was inhibited to a greater extent $(77 \%)$ than IgG1 TPO antibody (14\%). In contrast, in another patient (Fig. $6 \mathrm{~B}$ ), IgG1 TPO antibody binding was inhibited to a greater extent (62\%) than IgG4 TPO antibody (13\%). Data on a third patient are shown (Fig. $6 C$ ) because this serum was one of three with detectable IgG2 TPO antibodies. A small degree of inhibition of $\operatorname{IgG} 2$ was observed (29\%). The predominant inhibition for this patient was in the IgGl subclass.

As reported previously (32), the serum TPO autoantibodies studied were predominantly of kappa light chain type. Because SP2 is a kappa Fab fragment, it is not possible to assess inhibition of serum kappa autoantibody binding to TPO. However, we could investigate whether or not SP2 could compete with serum lambda TPO autoantibody binding to TPO. The extent of this inhibition was small, ranging from 12 to $18 \%$ in four sera.

Studies on the nature of the epitope recognized by TPO-specific Fab fragments. SP2 failed to recognize any plaques when used to screen a library of TPO cDNA fragments (66-166 amino acids in length) expressed in bacteria (34). In contrast, the positive control, murine monoclonal antibody \#40.28,

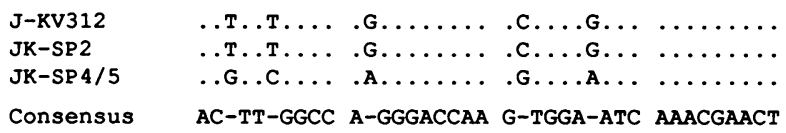

\begin{tabular}{|c|c|}
\hline J-KV312 & $\ldots \ldots \ldots \ldots \ldots$ \\
\hline JK-SP2 & $\ldots \ldots \ldots \ldots$ \\
\hline JK-SP 4/5 & .....v. . \\
\hline Consensus & TFGQGTKLEI KRT \\
\hline
\end{tabular}

Figure 3. Nucleotide and derived amino acid sequences for the JK regions of TPO Fab fragments SP2, SP4, SP5, the germline gene J$\mathrm{KV} 312$ (36) and the consensus sequence. Identity of residues is indicated by dots. reacted with $5 / \sim 2,000$ plaques. These data suggested that the epitope recognized by SP2 is nonlinear.

Confirmation that the epitope recognised by SP2 (and also by SP4 and SP5) is conformational was obtained in ELISA studies using native recombinant TPO and TPO denatured by reduction and alkylation. The three Fab fragments bound less well to denatured than to native TPO (Fig. 7). In contrast, binding of mouse monoclonal \#40.28 was higher to denatured than to intact TPO.

\section{Discussion}

The TPO-specific Fab fragments SP2, SP4 and SP5 all have the heavy chain variable region sequence previously reported for SP2 (23). The VH region is a member of the VHI family
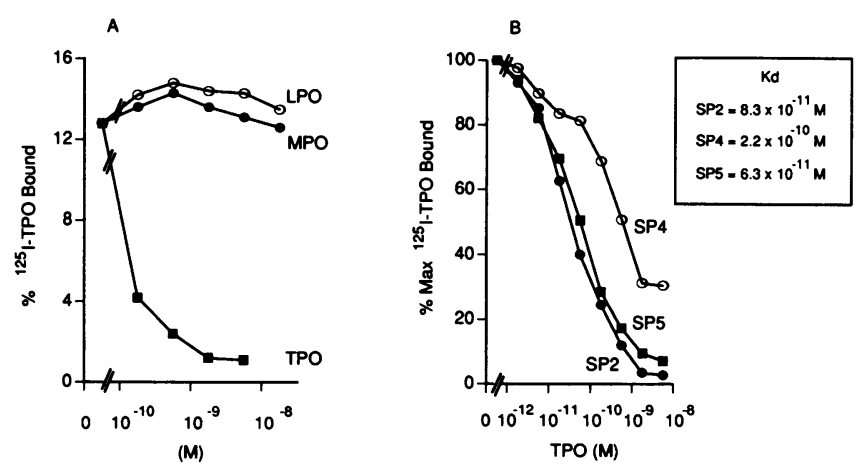

Figure 4. $(A)$ Effect of increasing molar $(M)$ concentrations of TPO, lactoperoxidase ( $L P O)$, or myeloperoxidase $(M P O)$ on the binding of ${ }^{125} \mathrm{I}$-TPO by SP2. Background binding in the absence of Fab fragments $(\sim 2 \%)$ was subtracted. $(B)$ Competition inhibition by unlabeled TPO of radiolabeled TPO binding to the Fab fragments. In the absence of unlabeled TPO, binding values for the three Fab fragments were $13-15 \%$. Background binding of $\sim 2 \%$ was subtracted. $K_{d}$ were determined by Scatchard analysis ( 30 ) and are shown in the box. 


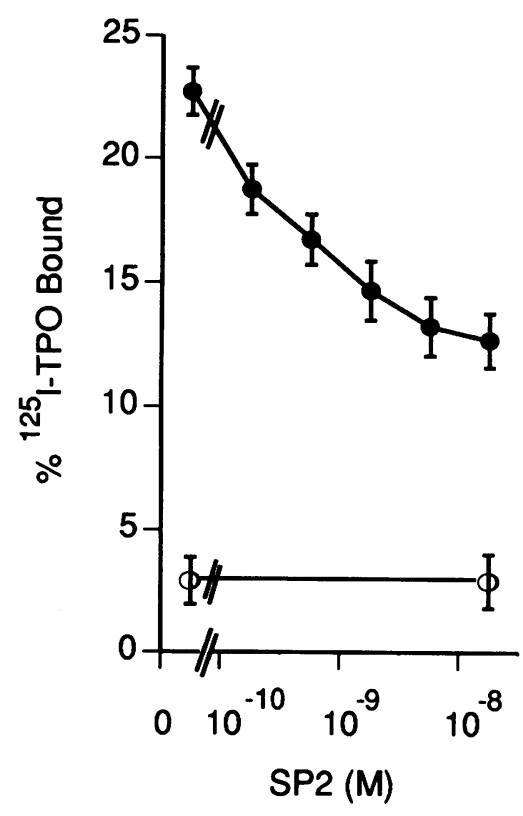

Figure 5. Inhibition by increasing molar $(M)$ concentrations of SP2 on the binding to ${ }^{125} \mathrm{I}$ TPO by serum TPO autoantibodies. The mean values $( \pm$ SEM $)$ obtained for sera from 11 patients are shown by solid circles. Background binding by serum from a TPO autoantibody negative donor was not subtracted and is shown by the open circles ( mean \pm SEM of three experiments).

(91.2\% homologous to the 1-1 germline gene) and the $\mathbf{J}$ segment is a $\mathrm{JH} 3$ with a truncation at its $5^{\prime}$ end (39). Because of its contribution to $\mathrm{CDR} 3$, the $\mathrm{D}$ region of these high affinity antibodies, which is not a member of any families reported, is of interest. The SP D region does not appear to result from homologous recombination (40) of known D segments. However, there is modest homology with a portion of the very long $\mathrm{D}$ segment of a cytomegalovirus antibody (41) and SP D shares the motif GGTAT in families $D_{M}, D_{N}$, and $D_{L R}$, and the motifs TACTA and GTATG in $D_{L R}(39)$.

The light chains of SP2, SP4, and SP5, though not identical, are closely related, moderately mutated members of the VKI and JK2 families. There is no relationship between the extent of mutation from the germline gene and their affinities for TPO. Overall, in accordance with previous data (42), the sequence information for both SP heavy and light chains suggests that one chain, in this case the heavy chain, is primarily responsible for SP specificity.

The SP Fab fragments were isolated from a library containing random combinations of heavy and light chain gene fragments. Therefore, it is not possible to determine whether or not the heavy and light chain combinations of the SP Fab fragments were present in vivo in the patient whose thyroid infil- trating B cells were used to construct the combinatorial library. Nevertheless, the Fab fragments, particularly SP5 and SP2, have very high affinities for TPO, comparable to the highest affinity TPO autoantibodies reported for serum (9). For this reason, as well as because of their derivation from a patient with autoimmune thyroid disease, the SP Fab fragments are suitable for investigating the interaction between TPO and serum TPO autoantibodies.

The ability of the SP Fab fragments to inhibit the binding to TPO of serum autoantibodies demonstrates identity or overlap between the Fab epitope and an epitope recognized by serum autoantibodies. Because this inhibition was observed for all 11 patients' sera examined, the epitope is very common in the TPO autoantibody repertoire. The prevalence in the patient population of autoantibodies recognizing linear epitopes on TPO is lower, being approximately $65 \%$ (43) and $58 \%$ (44) for the epitopes corresponding to TPO amino acids amino acids 590-622 (15) and 713-721 $(15,16)$.

The present data indicate that the SP epitope is recognized by $36-72 \%$ of the TPO autoantibodies present in the sera of individual patients. As yet, there is no information of the proportion of TPO autoantibodies within an individual patient which recognize one or both of the linear epitopes mentioned above. The present data also indicate that patients' autoantibodies against the SP epitope are not restricted to a single IgG subclass. Thus, in some patients the SP epitope is predominantly $\mathrm{IgG} 1$, in others $\mathrm{IgG} 4$, and in a few IgG2. IgG3 TPO autoantibodies are only rarely present $(32,38)$. There is no information on the IgG subclass distribution or light chain type of autoantibodies against the linear epitopes described above. In terms of light chain type, the SP epitope is recognized poorly by TPO autoantibodies with lambda light chains. The SP epitope-recognizing antibodies in the patient population are, therefore, likely to contain kappa light chains, like the SP Fab fragments themselves.

Techniques previously available to study TPO epitopes, such as the use of synthetic peptides, proteolytic fragments, and recombinant TPO fragments generated by cDNA libraries, are only capable of identifying linear epitopes. The most important new information provided by our data is that the SP epitope, recognized by very common and abundant TPO autoantibodies, is not linear but is conformational. Crystallization of the complex between recombinant TPO-specific Fab fragments and recombinant TPO will ultimately permit the definition of the amino acids involved in the highly conformational epitopes on TPO.
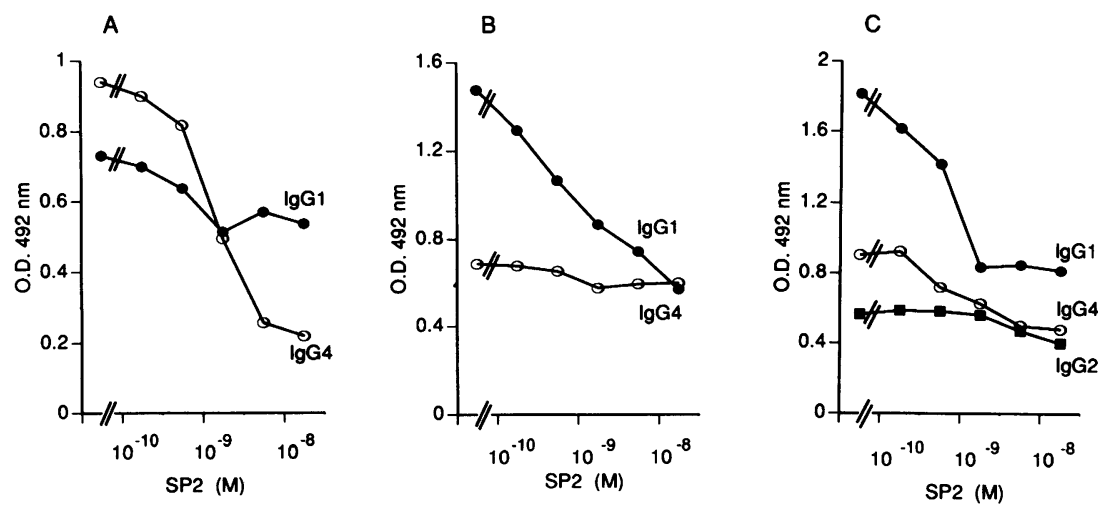

Figure 6. Competition ELISA for binding to TPO between the SP2 Fab fragment and TPO autoantibodies of different IgG subclasses. Panels $A, B$, and $C$ show data obtained with three different patients. TPO autoantibody levels are shown as the OD readings measured at $492 \mathrm{~nm}$. Background OD values obtained for TPO autoantibody-negative serum were $<0.05$. SP2 $(M)$; molar concentration of SP2. 


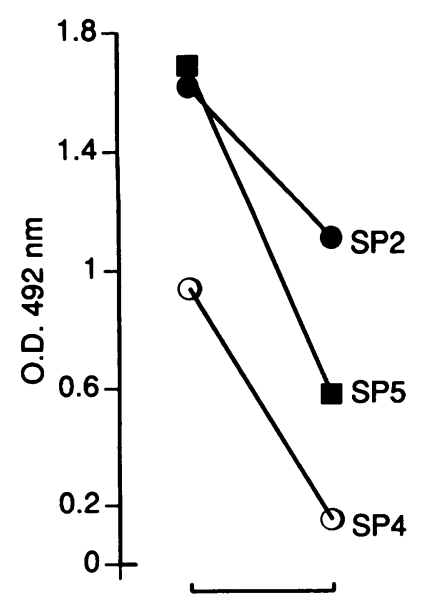

Native Denatured

TPO

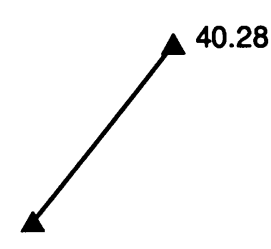

Native

Denatured

TPO

Figure 7. Effect of denaturation of TPO on SP Fab fragment binding. Binding of SP2, SP4, and SP5 (left panel) or mouse monoclonal antibody \#40.28 (right panel) was measured to native or denatured TPO by ELISA. Binding is shown as the OD value at $492 \mathrm{~nm}$. Background OD values for TPO autoantibody negative serum and control murine ascites were $<0.05$.

\section{Acknowledgments}

We thank Dr. Leslie DeGroot of the University of Chicago for kindly providing monoclonal antibody $\# 40.28$.

These studies were supported by National Institutes of Health grants DK-36182 and EY-09498.

\section{References}

1. Kimura, S., T. Kotani, O. W. McBride, K. Umeki, K. Hirai, T. Nakayama, and S. Ohtaki. 1987. Human thyroid peroxidase: complete cDNA and protein sequence, chromosome mapping, and identification of two alternately spliced mRNAs. Proc. Natl. Acad. Sci. USA. 84:5555-5559.

2. Magnusson, R. P., G. D. Chazenbalk, J. Gestautas, P. Seto, S. Filetti, L. J. DeGroot, and B. Rapoport. 1987. Molecular cloning of the complementary deoxyribonucleic acid for human thyroid peroxidase. Mol. Endocrinol. 1:856-861.

3. Libert, F., J. Ruel, M. Ludgate, S. Swillens, N. Alexander, G. Vassart, and C. Dinsart. 1987. Thyroperoxidase, an auto-antigen with a mosaic structure made of nuclear and mitochondrial gene modules. EMBO (Eur. Mol. Biol. Organ.) J. 6:4193-4196.

4. Portmann, L., N. Hamada, G. Heinrich, and L. J. DeGroot. 1985. Anti-thyroid peroxidase antibody in patients with autoimmune thyroid disease: possible identity with antimicrosomal antibody. J. Clin. Endocrinol. \& Metab. 61:10011003.

5. Czarnocka, B., J. Ruf, M. Ferrand, P. Carayon, and S. Lissitzky. 1985. Purification of the human thyroid peroxidase and identification as the microsomal antigen in thyroid diseases. FEBS (Fed. Eur. Biochem. Soc.) Lett. 109:147-152.

6. Kotani, T., K. Umeki, S. Matsunaga, E. Kato, and S. Ohtaki. 1986. Detection of autoantibodies to thyroid peroxidase in autoimmune thyroid diseases by micro-ELISA and immunoblotting. J. Clin. Endocrinol. \& Metab. 62:928-933.

7. Seto, P., H. Hirayu, R. P. Magnusson, J. Gestautas, L. Portmann, L. J. DeGroot, and B. Rapoport. 1987. Isolation of a cDNA clone for the thyroid microsomal antigen: homology with the gene for thyroid peroxidase. J. Clin. Invest. 80:1205-1208.

8. Belyavin, G., and W. R. Trotter. 1959. Investigations of thyroid antigens reacting with Hashimoto sera. Lancet. i:648-652.

9. Beever, K., J. Bradbury, D. Phillips, S. M. McLachlan, C. Pegg, A. Goral, W. Overbeck, G. Feifel, and B. Rees Smith. 1989. Highly sensitive assays of autoantibodies to thyroglobulin and to thyroid peroxidase. Clin. Chem. 35:19491954.

10. Doniach, D. 1975. Humoral and genetic aspects of thyroid autoimmunity. Clin. Endocrinol. Metab. 4:267-285.

11. Bogner, U., H. Schleusener, and J. R. Wall. 1984. Antibody-dependent cell-mediated cytotoxicity against human thyroid cells in Hashimoto's thyroiditis but not Graves' disease. J. Clin. Endocrinol. Metab. 59:734-738.

12. Jansson, R., P. M. Thompson, F. Clark, and S. M. McLachlan. 1986. Association between thyroid microsomal antibodies of subclass IgG-1 and hypothyroidism in autoimmune postpartum thyroiditis. Clin. Exp. Immunol. 63:8086.

13. Kohno, Y., Y. Hiyama, N. Shimojo, H. Niimi, H. Nakajima, and T. Hosoya. 1986. Autoantibodies to thyroid peroxidase in patients with chronic thyroiditis: effect of antibody binding on enzyme activities. Clin. Exp. Immunol. 65:534-541.

14. Banga, J. P., N. Doble, R. W. S. Tomlinson, E. Odell, and A. M. McGregor. 1989. Thyroid microsomal/thyroid peroxidase autoantibodies show discrete patterns of cross-reactivity to myeloperoxidase lactoperoxidase and horseradish peroxidase. Immunology. 67:197-204.

15. Libert, F., M. Ludgate, C. Dinsart, and G. Vassart. 1991. Thyroperoxidase, but not the thyrotropin receptor, contains sequential epitopes recognized by autoantibodies in recombinant peptides expressed in the pUEX vector. J. Clin. Endocrinol. \& Metab. 73:857-860.

16. Finke, R., P. Seto, J. Ruf, P. Carayon, and B. Rapoport. 1991. Determination at the molecular level of a B-cell epitope on thyroid peroxidase likely to be associated with autoimmune thyroid disease. J. Clin. Endocrinol. \& Metab. 73:919-921.

17. Davies, D. R., and E. Padlan. 1990. Antibody-antigen complexes. Annu. Rev. Biochem. 59:439-473.

18. Laver, W. G., G. M. Air, R. G. Webster, and S. J. Smith-Gill. 1990. Epitopes on protein antigens: misconceptions and realities. Cell. 61:553-556.

19. Nakajima, Y., R. D. Howells, C. Pegg, E. Davies Jones, and B. Rees Smith. 1987. Structure activity analysis of microsomal antigen/thyroid peroxidase. Mol. Cell. Endocrinol. 53:15-23.

20. Gardas, A., and H. Domek. 1988. The effect of sulphydryl reagents on the human thyroid microsomal antigen. J. Endocrinol. Invest. 11:385-388.

21. Fukuma, N., V. B. Petersen, S. M. McLachlan, C. A. S. Pegg, and B. Rees Smith. 1991. Human monoclonal thyroglobulin autoantibodies of high affinity. I. Production, characterisation and interaction with murine monoclonal thyroglobulin antibodies. Autoimmunity. 10:291-295.

22. Huse, W. D., L. Sastry, S. A. Iverson, A. S. Kang, M. Alting-Mees, D. R. Burton, S. J. Benkovic, and R. A. Lerner. 1989. Generation of a large combinatorial library of the immunoglobulin repertoire in phage lambda. Science (Wash. DC). 246:1275-1281.

23. Portolano, S., P. Seto, G. D. Chazenbalk, Y. Nagayama, S. McLachlan, and B. Rapoport. 1991. A human Fab fragment specific for thyroid peroxidase generated by cloning thyroid lymphocyte-derived immunoglobulin genes in a bacteriophage lambda library. Biochem. Biophys. Res. Commun. 179:372-379.

24. Maniatis, T., E. F. Fritsch, and J. Sambrook. 1982. Molecular cloning: A Laboratory Manual. Cold Spring Harbor Laboratory Press, Cold Spring Harbor, NY.

25. Foti, D., K. D. Kaufman, G. Chazenbalk, and B. Rapoport. 1990. Generation of a biologically-active, secreted form of human thyroid peroxidase by sitedirected mutagenesis. Mol. Endocrinol. 4:786-791.

26. Salacinski, P. R. P., C. McLean, J. E. C. Sykes, V. V. Clement-Jones, and P. J. Lowry. 1981. Iodination of proteins, glycoproteins, and peptides using a solid-phase oxidizing agent, 1,3,4,6-tetrachloro-3 alpha, 6 alpha-diphenyl Glycoluril (Iodogen). Anal. Biochem. 117:136-146.

27. Sanger, F., S. Nicklen, and A. R. Coulson. 1977. DNA sequencing with chain terminating inhibitors. Proc. Natl. Acad. Sci. USA. 74:5463-5467.

28. Laemmli, U. K. 1970. Cleavage of structural proteins during the assembly of the head of bacteriophage T4. Nature (Lond.). 227:680-685.

29. Fukuma, N., S. M. McLachlan, V. B. Petersen, P. Kau, J. Bradbury, M. Devey, K. Bleasdale, P. Grabowski, and B. Rees Smith. 1989. Human thyroglobulin autoantibodies of subclasses IgG2 and IgG4 bind to different epitopes on thyroglobulin. Immunology. 67:129-131.

30. Scatchard, G. 1949. The attractions of proteins for small molecules and ions. Ann. NY Acad. Sci. 51:660-672.

31. Schardt, C. W., S. M. McLachlan, J. Matheson, and B. Rees Smith. 1982. An enzyme-linked immunoassay for thyroid microsomal antibodies. J. Immunol. Methods. 55:155-168.

32. Parkes, A. B., S. M. McLachlan, P. Bird, and B. Rees Smith. 1984. The distribution of microsomal and thyroglobulin antibody activity among the IgG subclasses. Clin. Exp. Immunol. 57:239-243.

33. Jefferis, R., C. B. Reimer, F. Skvaril, G. deLange, N. R. Ling, J. Lowe, M. R. Walker, D. J. Phillips, C. H. Aloisio, T. W. Wells, et al. 1985. Evaluation of monoclonal antibodies having specificity for human $\mathrm{IgG}$ sub-classes: results of an IUIS/WHO collaborative study. Immunol. Lett. 10:223-252.

34. Finke, R., P. Seto, and B. Rapoport. 1990. Evidence for the highly conformational nature of the epitope(s) on human thyroid peroxidase that are recognized by sera from patients with Hashimoto's thyroiditis. J. Clin. Endocrinol. \& Metab. 71:53-59.

35. Portmann, L., F. W. Fitch, W. Havran, N. Hamada, W. A. Franklin, and L. J. DeGroot. 1988. Characterization of the thyroid microsomal antigen, and its 
relationship to thyroid peroxidase, using monoclonal antibodies. J. Clin. Invest. 81:1217-1224.

36. Kipps, T. J., E. Tomhave, P. P. Chen, and R. I. Fox. 1989. Molecular characterization of a major autoantibody-associated cross-reactive idiotype in Sjogren's syndrome. J. Immunol. 142:4261-4268.

37. Smith-Gill, S. J., P. A. Hamel, T. B. Lovoie, and K. J. Dorrington. 1987 Contributions of immunoglobulin heavy and light chains to antibody specificity for lysozyme and two haptens. J. Immunol. 139:4135-4144.

38. Weetman, A. P., C. M. Black, S. B. Cohen, R. Tomlinson, J. P. Banga, and C. B. Reimer. 1989. Affinity purification of IgG subclasses and the distribution of thyroid auto-antibody reactivity in Hashimoto's thyroiditis. Scand. J. Immunol. 30:73-82.

39. Pascual, V., and J. D. Capra. 1991. Human immunoglobulin heavy chain variable region genes: organization, polymorphism and expression. $A d v$. Im munol. 49:1-74.

40. Sanz, I. 1991. Multiple mechanisms participate in the generation of diversity of human H chain CDR3 regions. J. Immunol. 14786:1720-1729.
41. Newkirk, M. M., H. Gram, G. F. Heinrich, L. Östberg, J. D. Capra, and R. L. Wasserman. 1988. Complete protein sequences of the variable regions of the cloned heavy and light chains of a human anti-cytomegalovirus antibody reveal a striking similarity to human monoclonal rheumatoid factors of the Wa idiotypic family. J. Clin. Invest. 81:1511-1518.

42. Kabat, E. A., and T. T. Wu. 1991. Identical V region amino acid sequences and segments of sequences in antibodies of different specificities. $J$. Immunol. 147:1709-1719.

43. Ludgate, M., S. Mariotti, F. Libert, C. Dinsart, P. Piccolo, F. Santini, J. Ruf, A. Pinchera, and G. Vassart. 1989. Antibodies to human thyroid peroxidase in autoimmune thyroid disease: studies with a cloned recombinant complementary deoxyribonucleic acid epitope. J. Clin. Endocrinol. \& Metab. 68:1091-1096.

44. Elisei, R., S. Mariotti, S. Swillens, G. Vassart, and M. Ludgate. 1990. Studies with recombinant autoepitopes of thyroid peroxidase: evidence suggesting an epitope shared between the thyroid and the gastric parietal cell. Autoimmunity. 8:65-70. 